\title{
Theme and thematic progression in learner English: A literature review $^{1}$
}

\section{Tema y progresión temática en el aprendiz de inglés: una revisión literaria}

Wei Jing, M.A.

Southwest University

Chongqing, China

interlaken@139.com

http://dx.doi.org/10.14483/udistrital.jour.calj.2014.1.a06

Received: 11-Dic-2013 / Accepted: 28-Feb-2014

To cite this article

Jing, W. (2014). Theme and thematic progression in learner English: A literature review. Colombian Applied Linguistics Journal, 16(1). $67-80$.

\begin{abstract}
Theme and thematic progression in learner English has been studied extensively. This paper reviews the literature of Theme and thematic progression in learner English. Related articles appearing in the international journals from 1994 to 2013 are gathered and analyzed so that the following four questions can be answered: (i) How can Theme and thematic progression improve coherence in learner English output? (ii) How do English learners deviate from English native speakers in Theme and thematic progression in their output? (iii) What factors contribute to English learners' deviation in use of Theme and thematic progression? (iv) How can instruction in Theme and thematic progression improve English learners' use of Theme and thematic progression? Observations are also provided. This review not only provides a synthesis of the related literature in Theme and thematic progression, but also points to issues that could be further addressed in this research area.
\end{abstract}

Keywords: learner English, Theme, thematic progression.

\section{Resumen}

Tema y progression temática en el aprendiz de inglés ha sido estudiado de manera extensiva. Este artículo revisa la bibliografía del Tema y progresión temática en el aprendiz de inglés. Artículos relacionados que han sido publicados en revistas internacionales desde 1994 hasta 2013 fueron recolectados y analizados para que estas preguntas puedan ser respondidas: (i) ¿Cómo puede el Tema y la progresión temática mejorar la coherencia en el resultado del aprendiz de inglés? (ii) ¿Cómo pueden apartarse los aprendices de inglés de los hablantes nativos de inglés en el Tema y progresión temática en sus resultados? (iii) ¿Qué factores contribuyen a la desviación de los aprendices de inglés que utilizan Tema y progresión temática? (iv) ¿Cómo las instrucciones en Tema y progresión temática mejorar el uso de Tema y progresión temática en los aprendices de inglés? Esta revisión no solo muestra una síntesis de la bibliografía relacionada con Tema y progresión temática, sino que también señala asuntos que podrían ser abordados en esta área de investigación.

Palabras clave: aprendiz de inglés, Tema, progresión temática.

1This paper is one of the research results of the project "Theme and thematic progression in Learner English" which is sponsored by the "Fundamental Research Funds for the Central Universities” (Grant No. SWU1409176) in 2014. 
The Theme is the starting point of a message, "that which the clause is about" (Halliday, 2000, p. 37). The Theme is followed by the Rheme, which is "part of the assembly of the new information that the text offers" (Cummings, 2003, p. 133). As the text unfolds, the Themes connect to the Themes and Rhemes of preceding clauses in various ways, picking up or repeating the important concepts and developing them further. These connections form patterns of thematic progression (Daneš, 1974) which make a significant contribution to the cohesion and coherence of a text. While native speakers of English may have acquired the appropriate use of Theme and thematic progression to produce coherent discourse when they grow up learning the language, learners of English as a foreign language are yet to learn what kind of information to place in the Theme position and how to continually pick up the information which is already in the text and repeat it in some way so that the reader is always aware of the key concepts and how the these concepts are being developed (Hyland, 2004). Scholars study Theme and thematic progression in learner English in order to find out how English learners locate, orient, and develop the messages in their English output.

This literature review surveyed the articles regarding Theme and thematic progression in learner English appearing in international journals for the last two decades between the years 1994 and 20132? . Based on the articles collected, four issues are examined, including: (i) How can Theme and thematic progression improve coherence in learner English output? (ii) How do English learners deviate from English native speakers in Theme and thematic progression in their English output? (iii) What factors contribute to English learners' deviation in the use of Theme and thematic progression? (iv) How can instruction in Theme and thematic progression improve English learners' use in these areas?

The paper is organized as follows. I first examine how appropriate use of Theme and thematic progression improve coherence in learner English output. Then I review comparison studies in Theme and thematic progression between learner English speech/writing and English native-speaker speech/writing. After reviewing

2 The major databases for the sources cited in this literature review include Cambridge Journal Online, CNKI, EBSCO, Gale, Google Scholar, JSTOR, ProQuest Education Journals, ScienceDirect, Springer, and Wiley. the literature which investigates the factors influencing English learners' Theme and thematic progression, I review the empirical studies which have investigated the effect of instruction in English learners' use of Theme and thematic progression. I also provide observations and suggestions for future work before concluding the paper.

\section{Theme and Thematic Progression and Coheren-} ce in Learner English Writing

Coherence is thought of as the relationship between different semantic meanings in a text (Canale, 1983) and many scholars agree that the key element that both writers and readers draw on in creating and interpreting these semantic relationships is their prior knowledge. Another important element in establishing clear semantic relationships is ordering ideas in a logical sequence, which is an aspect of coherence that has been emphasized in many discussions of text coherence (Bander, 1983). According to Dastjerdi and Talebinezhad (2006), a text is coherent "when it hangs together, i.e., for every sentence in the text, there is a sequence of preceding and/or following sentences that provides a 'context' for it" (p. 59). One line of research in Theme and thematic progression in learner English focuses on how appropriate use of Theme and thematic progression improve coherence in learner English output, mainly learner English writing, by analyzing their problems in the use of Theme and thematic progression.

Ma (2001) and Wang (2010) illustrated how appropriate use of Theme and thematic progression contributed to coherence in learner English writing by comparing writing that was graded with high, medium, and low scores. It was found $(\mathrm{Ma}, 2001)$ that English writing that was graded with high scores was more coherent, using different types of thematic progression such as constant thematic progression and linear thematic progression than writing that was graded with low scores in a comparison study of three writing samples taken from CET-4 and CET-63를 writing

3 CET-4, CET-6 and TEM-4 are the short forms for "College English Test Band 4", "College English Test Band 6" and "Test for English Majors Band 4". As English as a foreign language tests in the People's Republic of China, their purpose is to examine the English proficiency of undergraduate students and postgraduate students in China. 
sections. Wang (2010) concluded that the use of more multiple Theme, clausal Theme, and effective thematic progression patterns such as constant progression, linear progression, split Theme progression, and split Rheme progression could make English writing more coherent, based on a detailed analysis of three writing samples that were graded with high, medium, and low scores from TEM-42 writing sections.

Cheng (2002) and Zhang (2004) identified the problematic use of Theme and thematic progression in Chinese English learner writing and showed how coherence in such writing could be improved by revising the problems with the use of Theme and thematic progression. Cheng (2002) contended that a major reason for the lack of coherence in Chinese students' English writing was inappropriate thematic choices and thematic progression. He found that one third of the 58 student writing samples under investigation featured infrequent use of Themes that were not connected either to preceding Themes or succeeding Themes and thematic progressions that had not yet been identified. Zhang (2004) examined a total of 50 English writing samples produced by 50 second year college English majors and found that $42.07 \%$ of the Themes were confusing, which led to incoherence in writing. She also found the same problems that Cheng (2002) identified in learner writings, i.e., Themes that were not connected either to preceding Themes or succeeding Themes. Other problems include Themes that were not key concepts of the writing or not relevant to the topic for writing, and Themes that did not help develop the writing.

Green, Christopher, and Lam (2000) analyzed texts containing marked Themes; the effects of the markedness on information structure were determined in their study investigating sentence-initial position, certain topic-fronting devices, and logical connectors in a non-native speaker corpus produced by Chinese subjects, with English native speakers as research baseline. It was found that inappropriate occupation of Theme position by the items under consideration here had a deleterious effect on information structure and that this, in turn, had negative effects on both local and global text coherence.

Mellos (2011) demonstrated that Theme-Rheme choices characterized coherence in writing by analyzing the Theme/Rheme patterns in eight undergraduate ESL essays, four of which were evaluated as being high in coherence and four of which were low in coherence. The study found that the more coherent essays employed dense and complex nominal groups in ideational Themes, a wide variety of textual Themes, and different forms of thematic progression to establish connections between different parts of the text and comment on abstract ideas relevant to the topic. In contrast, the less coherent writing frequently overused unmarked Themes of simple nominal groups or pronouns and Theme reiteration in a way that made the text difficult to follow and appear to lack development.

\section{Comparison Studies of Theme and Thematic Progression in English Learner Speech/wri- tings and Native-speaker Speech/writings}

Wei (2013a) investigated how intermediate Chinese English learners used Themes differently from advanced Chinese English learners in their English speech. The corpus consisted of comparable spoken data of intermediate Chinese English learners, advanced Chinese English learners, and English native speakers. Halliday's (2000) model of thematic organization was used to analyze the gathered data for Theme types and Theme markedness. The results of the study revealed that as the length of time learning English increases, the learners became better at making Theme choices: they displayed closer performance to native speakers in Theme choices in terms of the frequency of topical Themes, textual Themes, interpersonal Themes, and Theme markedness.

\section{Comparison studies of Theme and thematic progression of English learner writings and native-speaker writings}

While discourse is co-constructed by interlocutors in conversations, and there are more opportunities to negotiate meaning if the information is not shared or given between the interlocutors (Bloor E Bloor, 1992), meaning is not co-created in writing, thus it requires additional and diverse grammatical strategies to effectively exploit the Theme position of a sentence to create coherent texts (Egg- 
ins, 2004; Schleppegrel, 2004). This is probably why more scholars are interested in comparing Theme and thematic progression of learner English writing and native-speaker writing. The studies focus on Themes, thematic progression, or both Theme and thematic progression. Some studies were corpus based and other studies used data collected specifically for studying Theme and thematic progression. The English learners that were investigated came from a number of different native language backgrounds: Chinese, Dutch, Finnish, German, Iran, Norwegian, Polish and Swedish. I will review these studies by research focus.

Ventola (1994), Green et al (2000), Hu (2008), Ebrahimi and Ebrahimi (2012b), Lu (2013), and Wei (2013b) investigated Theme in learner English writing in their studies. These studies showed that English learners deviated from English native speakers for they overused certain Themes, mainly interpersonal Themes, textual Themes, and marked Themes, and underused certain Themes such as topical Themes. It was also reported that learners from different language backgrounds displayed similar performances in use of Theme and thematic progression.

Ventola (1994) illustrated that Finnish writers tended to have difficulties in coding references to text participants appropriately in their English texts. When organizing their texts thematically, Finnish writers also appeared to apply thematic patterns which were not typical of English texts. In addition, Finnish writers did not seem to utilize the possibilities of the interplay between the Reference and Theme systems at their textual optimum.

Green et al (2000) investigated sentence-initial position, certain topic-fronting devices (beginning for and concerning), and logical connectors (besides, furthermore, and moreover) in a non-native speaker (NNS) corpus produced by Chinese subjects, with an English native-speakers corpus as a research baseline. The findings demonstrated that Chinese subjects did have a greater tendency than native speakers to place the connectors under consideration in Theme position. This empirical study was followed by an exercise in which texts containing marked Themes were analyzed to determine the effects of markedness on information structure.
It was found that inappropriate occupation of Theme position by the items under consideration here had a deleterious effect on information structure and that this, in turn, had negative effects on both local and global text coherence.

Hu (2008) conducted a comparison study between American college students' English writing and Chinese college students' English writing in terms of simple Themes, multiple Themes, and clausal Themes. She found that Chinese college students used less simple Themes but more multiple Themes and clausal Themes than American college students. In multiple Themes, Chinese college students sometimes overused textual Themes such as "and," "but," "however," etc., which was explained by an overgeneralization of English grammar rules. They also put a lot of temporal adjuncts and spatial adjuncts at the beginning of a clause, especially spatial terms such as "at the school" or temporal terms such as "last year," which was explained by the interference of Chinese, their native language.

Lu (2013) compared Theme choices in English writings of Singaporean students from an Englishspeaking background (SE), Singaporean students from a Chinese-speaking background (SC), and students from the People's Republic of China (PRC) at the university level. It was found that SC and PRC students used less topical Themes than SE students, that PRC students used less textual Themes than both SC and SE students, and that PRC students used less interpersonal Themes than both SE and SC students. The author found that the writing of Singaporean and Chinese students did produce various interesting similarities and differences and attributed these similarities and differences to their sociolinguistic and educational backgrounds. The findings of this study suggested that English learners of different background (in this case, English learners of Chinese-speaking background in mainland China and those from Singapore) exhibited closer performance to each other as compared to native English speakers.

Wei (2013b) investigated topical Theme choices in Chinese and Swedish English learners' English writings and aimed to examine how topical Theme choices in Chinese English learners' English writings 
were different from those in Swedish English learners' English writings with native-speaker writings as the research baseline. The corpus consisted of comparable written data of Chinese English learners, Swedish English learners, and native speakers of English. The results of the study revealed that the two groups of English learners exhibited more similarities in topical Theme choices than differences. They displayed closer performance to each other not only in all three types of topical Themes, but also in two of the five elements in informational Themes, two of the three elements in interactional Themes, and all three elements in discoursal Themes.

Ebrahimi and Ebrahimi (2012a), Rørvik (2012), and Medve and Takač (2013) compared the use of thematic progression in learner English writing and native-speaker writing. These studies revealed that native language backgrounds, cultural backgrounds, and academic writing experiences might influence the way in which English learners used thematic progression (Ebrahimi E Ebrahimi, 2012a; Ebrahimi E Ebrahimi, 2012b; Lu, 2013).

Ebrahimi and Ebrahimi (2012a) compared thematic progression patterns in $180 \mathrm{EFL}$ compositions by 60 Iranian students majoring in Teaching English as a Foreign Language with different academic writing experiences, using McCabe's (1999, as cited in Ebrahimi \& Ebrahimi, 2012a) model of thematic progression. The results illustrated significant differences between the three groups regarding their use of linear and constant patterns of progression. The authors reported that there were significantly more linear and constant patterns in the writings by the senior group who had received instruction on grammar, paragraph writing, and essay writing than in the writings by the other two groups. It was also found that junior students who received instruction on grammar and paragraph writing were more likely to use these patterns than sophomore students who received only instruction on grammar as well. They justified such a tendency in light of academic writing experience being one of the factors which influenced the production of a more cohesive text applying such cohesive devices.

Rørvik (2012) examined the use of thematic progression in data from the Norwegian component of the International Corpus of Learner English (NICLE) to investigate whether Norwegian advanced learners of English used the same thematic progression strategies as native-speaker professional writers of English, or whether they were influenced by Norwegian discourse conventions using the Integrated Contrastive Model. The influence of transfer was also examined through comparison with Norwegian texts written by professional writers. In addition, a comparison with non-professional writers of English and Norwegian was included in order to identify potential similarities between novice writers, regardless of whether or not they are writing in their L1 or L2. The results indicated that there were differences in the use of thematic progression strategies between the NICLE writers and professional writers of English, and that some of these differences were most likely due to transfer from Norwegian. In addition, novice writers seemed to share certain characteristics in the way they structured their texts which were different from the strategies employed by professional writers.

Medve and Takač (2013) explored the ways in which foreign language learners used cohesion and coherence in their written production based on a sample comprising 90 assignments written by 30 learners of English as a foreign language, 30 learners of German as a foreign language, and 14 learners of both foreign languages, in order to find out which progressions (parallel, sequential, extended parallel progression, and extended sequential progression) were used by participants in connecting ideas and thoughts within the paragraphs. The findings showed that sequential progression (SP) of sentences was the dominant progression type in this corpus. The other three types of progressions-parallel progression (PP), extended sequential progression (ESP), and extended parallel progression (EPP) were used less frequently. An independent t-test showed that there were no statistically significant differences in progression type scores for learners of English and learners of German. It was also concluded that successful learners tended to use sequential progression more often than unsuccessful learners.

Belmonte and McCabe-Hidalgo (1998), Qian, Andrés Ramírez, and Harman (2007), Jalilifar (2010a), and Herriman (2011) compared both Theme and thematic progression in learner English writing and native-speaker writing. These studies found 
deviation of both Themes and thematic progression in learner English writing from native-speaker writing.

Belmonte and McCabe-Hidalgo (1998) analyzed a sample of 25 student compositions written by Spanish native speakers learning English as a second language in terms of their Themes and thematic progression and uncovered common problems for textual cohesion and coherence in Themes and thematic progression in learner English writing, including confusing selection of discoursal and topical Themes, overuse of There, brand new Theme, empty Rheme, Themes with unclear reference, and overuse of constant progression.

Qian et al. (2007) analyze Theme markedness and thematic progression in one Chinese college student's expository essay written on a nationwide English examination in China, using Systemic Functional Linguistics. These components were further explored through a parallel analysis of an expository essay written by one North American first year college student. It was found that the Chinese student used circumstantial elements as marked themes repeatedly, which limited her ability to use Linear Progression as another cohesive strategy. It was also reported that the Chinese student seemed to favor more emergent modes of textual organization such as conjunctive adverbs that were frequently overused by EFL/ESL students (Schleppegrell, 2004, as cited in Qian et al., 2007), leading to Themes without apparent textual cohesion as they did not draw on the Rheme of a previous clause for the Theme of the next clause.

Jalilifar (2010a) conducted a frequency and functional analysis of thematization of 90 college students' English compositions, based on Halliday's (1985, as cited in Jalilifar, 2010a) and McCabe's (1999, as cited in Jalilifar, 2010a) models of thematicity with an educated native speaker as a criterion measure. The results suggested thematically different compositions in terms of interpersonal, unmarked, simple, and multiple Themes and showed that students' level of language proficiency monitor the use of linear and split thematic progression chains.

Herriman (2011) investigated how Themes and thematic progressions in a sample of Swe- dish advanced learners' writing contributed to the method of development in their texts. With a comparison to a sample of similar writings by British university students, the author found that advanced learners' samples contained more interactional Themes, which created a dialogic method of development similar to that found in conversational language. Themes and thematic progressions which were typical of expository writing, on the other hand, were used less frequently. These included discourse label Themes and summative progressions which managed the build-up of information as it accumulated in the text, and split progressions which signaled hierarchical relations between parts of the informational content.

Theme and thematic progression of English research article abstracts written by nonEnglish-native scholars

Apart from learner English speech and learner English writing, some scholars are interested in how non-native-English scholars apply Themes and thematic progression in academic writings in English. It is noted that these studies are much needed because many non-native-English scholars express frustration with the rejection of their texts for publication, and the lack of insight into the exact problem with their writing (Martínez, 2003). Overall, ThemeRheme studies of published research articles contribute to our knowledge of disciplinary conventions and can inform teachers of academic writing. These studies found a deviation in use of Themes and thematic progression in the research article abstracts of non-native-English scholars. The findings also suggested that use of Theme and thematic progression is connected with the type of writing and the genre of studies.

Martínez (2003) conducted a study comparing the thematic structure of methods and discussion sections of biology research articles. Themes were analyzed using the categories of SFL in addition to a sub-classification of unmarked Themes into semantic categories similar to MacDonald's (1994, as cited in Martínez, 2003) and Gosden's (1993, as cited in Martínez, 2003) classifications. The study showed that the Themes in the methods section consisted of predominately simple unmarked ideational The- 
mes; when there were multiple Themes, they tended to be textual and temporal (e.g. first) (Martínez, 2003, p. 112). In the discussion section, there were more multiple Themes than in the methods section; ideational and textual Themes appeared more frequently, and the textual Themes tended to be more adversative (e.g. however) (Martínez, 2003, p. 112). The study also found differences in the use of marked Themes across sections. In the methods section, the marked Themes frequently were circumstances of purpose (e.g. to determine if...) and of time (e.g. after the process of...) while the marked Themes in the discussion section were mostly circumstances of place (e.g. in our model) (Martínez, 2003, p. 115). The results were attributed to the purpose of each section, namely that in the methods section, the purpose was to be descriptive while in the discussion section, it was to be more argumentative.

Lores (2004) applied thematic analysis in terms of thematic progression and method of thematic development to research article abstracts and found variations in thematic progression patterns that sustained their perception of distinct rhetorical structures. It was found that there was a combination of two main types of patterns (simple linear and constant), and a claim could be made that this combination was not random and that different sections or moves which constituted to each type of abstract seemed to display a distinct combination of thematic patterns, both within the moves or across boundaries between moves.

Jalilifar (2010b) compared different thematic types and thematic progression patterns used in different rhetorical sections of ELT, an international journal, and Roshd, a local, peer-reviewed journal in Iran, based on Halliday's (1985, as cited in Jalilifar, 2010b) categorization of Theme and the revised model of thematic progression patterns proposed by McCabe (1999, as cited in Jalilifar, 2010b). The analysis showed overall similarities in both journals regarding different types of Theme and patterns of thematic progression, which could be attributed to the shared genre. But the author also found significant differences in the number and the context of the usage of different patterns of thematic progression in the introduction, results, and discussion sections of both journals, indicating the descriptive nature of Roshd and argumentative nature of ELT journals. The results confirmed the need for informing local writers of English of the crucial role of thematic organization in the writing of ELT articles.

Ebrahimi and Khedri (2011) investigated how thematic structures were tackled by research article writers from different disciplines coming from different academic discourse communities while contributing their new knowledge in the abstract section of research articles. Following Halliday's (1994, as cited in Ebrahimi \& Khedri, 2011) model of thematic organization and the revised model of thematic progression pattern proposed by McCabe (1999, as cited in Ebrahim \& Khedri, 2011), they incorporated a corpus of 10 academic research article abstracts from two disciplines (five in Chemical Engineering and five in Applied Linguistics) so as to clarify the possible similarities and variations between these two disciplines in light of thematic selection. The result supported the hypothesis that academic research article abstracts were shaped by their disciplinary background.

Gao (2012) found higher percentage of nominalization in native writer writing samples, which served to organize texts and might be the reason for their fluency and coherence, by identifying, analyzing, and interpreting the nominalization in medical papers written by native English writers and Chinese writers from three aspects: the frequency of nominalization, lexical density, and thematic progression. The author further suggested that nominalization played a crucial role in building the logical structure of medical English papers and improving their formality, and proposed incorporating in teaching the use of nominalization, due to significantly insufficient use of nominalization in Chinese writers' medical papers.

Hawes and Thomas (2012) examined essays by pre-MA students of journalism, predominantly from East Asia, and compared their use of thematisation with that of the professional journalists. They discussed students' problems with Themes and proposed a focus on non-participant Themes, discourse participants, and also what they referred to as "disguised discourse participants." They also re- 
commended analyzing at least the rudiments of thematisation with students and presenting them with a Theme-Rheme "model" from their chosen genre - specifically a cline, based on quantitative thematisation data, stretching from a tabloid newspaper to a broadsheet, as a yardstick against which the appropriateness of student thematisation may be measured (Hawes \& Thomas, 2012, 175).

\section{The Factors that Influence English Learners' Themes and Thematic Progression}

So far, scholars have elaborated on how L1 transfer, proficiency level, disciplinary background, communication strategies, and target language input can influence English learners' use of Theme and thematic progression.

L1 transfer has always been a focus of study when it comes to the deviation of English learners' use of Theme and thematic progression. For example, Cai (1998) investigated the topic-prominent errors in English essays written by Chinese university students in a quantitative approach and found that more than $20 \%$ of the errors were results of L1 transfer. Bohnacker and Rosén (2008) found language-specific patterns in native-speaker corpora: the frequencies of prefield constituent types differed substantially between German and Swedish, and Swedish postponed new (Rhematic) information and instead filled the prefield with given (Thematic) elements and elements of no or low informational value (e.g., expletives) to a far greater extent than German in a study investigating information structure of verb-second declaratives in Swedish, German, and nonnative German. These learners over-applied the Swedish principle of Rheme later in their second language German, indicating first language (L1) transfer at the interface of syntax and information structure, especially for structures that were frequent in the L1. Hasselgård (2009a; 2009b) found that Norwegian EFL learners tended to thematize adverbials in writing, exhibiting features of the Norwegian pattern because Scandinavian languages, such as Norwegian and Swedish, were more flexible than English in terms of word order and allowed more room for fronting adverbials. Rørvik (2012) pointed out that differences in the use of thematic progression strategies between the NICLE writers and pro- fessional writers of English were most probably due to transfer from Norwegian through comparison with Norwegian texts written by professional writers in a study examining the use of thematic progression in material from the Norwegian component of the International Corpus of Learner English (NICLE).

Proficiency level has also been examined as an influencing factor in a number of studies. Bohnacker (2010) found a substantial increase in clauseinitial expletive subjects, clefts, and lightweight given elements in Swedish learner English, which was thought to be indicative of development towards the target language in a study investigating Theme-Rheme (old vs. new information) in L2 Swedish writings. Wei (2013a) found that English learners became better at making Theme choices and moved closer to native speakers in topical Themes, textual Themes, and Theme markedness with increased length of time learning English in a study investigating the development of Theme choices in learner English speech from a lower language proficiency level to a higher language proficiency level.

North (2005) examined whether the students' use of Theme might vary according to their disciplinary background using a systemic functional approach for analysis of essays written within an open university course in the history of science. It is found that students from an arts background achieved significantly higher grades than those from a science background. This could be related to a greater tendency to present knowledge as constructed, using Themes which framed the discussion as a matter of interpretation rather than fact. The results supported the hypothesis that student writing was shaped by their disciplinary background, suggesting that success in writing for one course might be affected by writing experiences in previous courses. Similar results were reported in Ebrahimi and Khedri (2011) when they investigated how thematic structures were tackled by research article writers from different disciplines coming from different academic discourse communities while contributing their new knowledge in the abstract section of research articles. Based on a corpus of 10 academic research article abstracts from two disciplines (five in Chemical Engineering and five in Applied Linguistics), it was found that academic research article abstracts were shaped by the author's disciplinary background. 
Ebrahimi and Ebrahimi (2012a) tried to justify that previous academic experience could be one of the factors which influenced producing a more cohesive text applying Theme and thematic progression by examining 180 compositions by 60 students majoring in Teaching English as a Foreign Language from three different language proficiency levels. The results illustrated significant differences between the three groups regarding their use of linear and constant patterns of progression. It was reported that the senior group who received instruction on grammar, paragraph writing, and essay writing used more linear and constant patterns than the other two groups. Furthermore, the preference of junior students who received instruction on grammar and paragraph writing towards using these patterns was also greater than sophomore students who received only instruction on grammar as well. It was therefore concluded that academic writing experience was one of the factors which influenced producing a more cohesive text applying such devices.

Chen (2010) discussed how communication strategies and target language input could affect the way in which Chinese English learners decided which information to place in Theme position in her study investigating the features of Theme of Chinese advanced learners in spontaneous speech. She regarded thematized adjuncts and interpersonal Themes as time-winning communicative strategies in learner speech, which was also found to be a systematic feature common among Chinese advanced learners regardless of task types and proficiency levels. She also provided examples of grammar exercises for adverbial clauses of time and the past-perfect tense taken from English textbooks (Book 2, New Standard English) used in senior middle schools in China. These examples demonstrated misleading input of other aspects of the language where formal rules and semantic relationships were emphasized at the expense of discourse principles.

\section{Instruction in Theme / Thematic Progression}

There has been a consensus that instruction in Theme and thematic progression should be included in the teaching of English. For example, Ventola (1994) advocated that courses for academic writing in a foreign language should develop learners' cons- ciousness and linguistic skills in organizing information in texts in a way that is referentially and thematically cohesive. Cheng (2002) proposed that the theory of Theme and thematic progression should be included in English teaching to Chinese students in his study investigating how problems with thematic progression would compromise coherence in Chinese English learners' writings. Alonso and McCabe (2003) pointed out that learners often wrote essays that consisted of sentences which did not seem to connect together into a cohesive text, and claimed that while ELT writing materials provided some focus on cohesive devices, little attention was paid to the progression of information in texts. Wang (2007) claimed that Theme-Rheme theory was a valuable tool for teachers to diagnose writing difficulties and students could be taught how to arrange old and new information to help improve cohesion in their writing. Christie and Dreyfus (2007, p. 245) advocated a genre-based approach to teaching which included deconstructing genre models for Theme and thematic progression among other things. Bohnacker (2010) pointed out that "discourse-driven word order patterns are ... largely ignored in descriptive grammars, teacher training and language teaching materials" (p. 133) while the learners were not likely to be monitored for differences concerning the interaction of information-structure and word order, as they were probably not aware that Swedish differed from German in this regard. In their paper examining the writing of pre-MA students, Hawes and Thomas (2012) proposed that "there is a need for coaching in thematisation, based on our students' apparent inadequate familiarity with English information structure" (p. 182), comparing their use of thematisation with that in the two newspapers The Sun and The Times.

In contrast, however, there has been very little specific information regarding how teachers can go about applying the theory of Theme and thematic progression (Wang, 2007). Very few studies have developed and studied teaching materials informed by Theme-Rheme (Bonhnacker, 2010), and a very limited number of studies have attempted to investigate with empirical evidence how instruction in Theme and thematic progression can enhance coherence in English learner writing, and there has been no such empirical studies in English learner speech at all. 
Mellos (2011) presented classroom activities that introduced students to the grammar of ThemeRheme in order to improve the coherence of their writing with a model of Theme-Rheme analytical framework in the academic writing curriculum. Comprised of five parts, introduction to Theme-Rheme, analysis of authentic and model texts, introduction to Thematic patterns, analysis of Theme patterns in student texts, and application to the students' writing, the lessons were intended for an undergraduate ESL academic reading and writing course and with adaptation could be used for other levels and contexts.

Cheng (2008) investigated the effects of genrebased pedagogy on L2 student writing development by incorporating "analyzing Theme choices" as part of the three-stage EFL composition course in Taiwan with college freshmen learning how to write narrative text. The results indicated that students' essays exhibited pre- to posttest gains in content development and textual coherence. Ho (2009) investigated how helping students analyze the macro and micro elements following Systemic Textual Analysis (STA) of a text helped them improve the overall structure and texture of their own writing by comparing the written assignments in pre-instruction sessions and post-instruction sessions produced by one ESL undergraduate student in the English class. The comparison revealed that a STA approach to instruction has helped to improve the structure and texture of her review writing in terms of the schematic and clause structure of such a text type. The variation between the two texts indicated that the student was attempting to improve the texture on her second attempt. The writer pointed out that STA, like many other methods of instruction, required time for results from instruction to emerge and to expect positive changes overnight or instantly would be quite unreasonable.

While Ho's study is based on only two writings from a single participant, thus low in its representativeness, Liu and Liu (2013) verified the validity of the application of Theme theory in teaching English writing in an experiment with 50 participants. They employed a pre-test and post-test in the study and compared how the experimental group and the control group differed before and after the 16-hour training in Theme/Rheme and thematic progression which lasted eight weeks in their use of six types of thematic progression. The findings suggested that writing coherence relied on the success of thematic structure of texts and that the significant progress of writing coherence contributed to the significant improvement on overall writing proficiency.

However, Liu and Liu (2013) included only thematic progression patterns which promoted text development, i.e., linear progression, constant progression, focused progression, derived-Theme progression, split-Rheme progression, and summarized progression for both pre-test analysis and post-test analysis. From the statistics provided in the study, these six types of thematic progression patterns accounted for all the thematic progression in learner English writing. The exclusion from their analytical model of the Themes that do not promote text development, i.e., back Themes, new Themes and contextual Themes, compromised the conclusion from their study.

\section{Observations}

We examined the articles investigating Theme and thematic progression in learner English which were published in international journals in the period between 1994 and 2013. The studies center on four aspects: how Theme and thematic progression help with cohesion and coherence in learner English output, how learner English output deviates in use of Theme and thematic progression from native English output, the factors which influence English learners' use of Theme and thematic progression in the target language output, and how instruction in Theme and thematic progression helps English learners with their use of Theme and thematic progression. Observations based on these journal articles are made in research focus, research subjects, research methods, and future work.

\section{Research focus}

The earliest studies have focused on Theme types in learner English, and later, scholars examined thematic progression in learner English. However, a more complete picture of how English learners construct messages in English output is provided by 
studies investigating both Theme types and thematic progression in learner English. A recent trend in this research area is to see how instruction in Theme and thematic progression might affect the way learners construct their message in English output.

In terms of the type of learner English output, there have been studies of learner English writing and learner English speech; however, there are more studies in learner English writing than learner English speech. Of all the studies examined in this review, only two investigated learner English speech, both of which focused on Theme types only.

\section{Research subjects}

Scholars have always been interested in English learners' use of Theme and thematic progression in the target language writings and speech produced by university students; however, they have come to realize the value of the study of Theme and thematic progression in English academic articles produced by non-native English scholars as more and more non-native English scholars are publishing research articles in English around the world and need to be aware of using Theme and thematic progression to create more cohesive texts to communicate more effectively with other scholars internationally.

Change of participants' language background may signal a change in research focus, too. There have been many studies comparing Theme and thematic progression between one group of learners and native speakers, but now scholars also make comparison studies in the use of Theme and thematic progression of learners from different native language backgrounds, with the data of native speakers as the research baseline.

\section{Research methods}

The early literature on Theme and thematic progression was mostly done on a small scale and usually in a qualitative manner. Later, scholars began to use quantitative means to compare the frequency of Theme types and thematic progression in learner English output on a somewhat larger scale, although usually limited to 30 samples for one group due to the exces- sive workload of analysis. The quantitative studies are usually combined with qualitative analyses.

\section{Future work}

Although much work has been done in investigating Theme and thematic progression in learner English, a number of questions need to be addressed. To begin with, we need a more detailed description of how Chinese learners of English deviate from native speakers in the use of both Theme and thematic progression, using a combination of quantitative and qualitative methods. The past studies investigated only Themes in Chinese learners' English output. In addition, we need more studies which investigate how instruction in Theme and thematic progression might affect learners' use in these two aspects as well as the coherence in their English writing.

\section{Conclusion}

This paper is based on a literature review of Theme and thematic progression in English Learner output. It is demonstrated that scholars have studied how appropriate Theme choices and thematic progression patterns help make learner output more coherent and cohesive, that English learners use Theme and thematic progression differently from native speakers, which accounts for the incoherence in their writing, that English learners' use of Theme and thematic progression from native speakers may be influenced by L1 transfer, proficiency level, disciplinary background, communication strategies, and target language input, and that instruction in Theme and thematic progression has positive effects on English learners' use of Theme and thematic progression, thus improving coherence in writing. I then made observations in terms of research focus, research subjects, and research methods. It is also pointed out that we need more studies to have a better picture of how Chinese English learners use Theme and thematic progression in their English output, as well as more studies to verify the effect of instruction in Theme and thematic progression on learner output. This can definitely aid teachers and scholars in teaching English writing and carrying out studies in Theme and thematic progression. 


\section{Acknowledgements}

I would like to thank the editors for their meticulous work and timely decisions, and the reviewers for their valuable comments and suggestions on an earlier version of this paper.Online, CNKI, EBSCO, Gale, Google Scholar, JSTOR, ProQuest Education Journals, ScienceDirect, Springer, and Wiley.

\section{References}

Alonso, S., \& McCabe, A. (2003). Improving text flow in ESL learner compositions. The Internet TESL Journal, 9 (2). Retrieved from http://iteslj.org/Articles/ Alonso-ImprovingFlow.html.

Bander, R. G. (1983). American English rethoric (3rd edition). New York: Holt, Rinehart and Winston.

Belmonte, I. A., \& McCabe-Hidalgo, A. (1998). ThemeRheme patterns in L2 writing. Didáctica, 10, 13-31.

Bloor, M., \& Bloor, T. (1992). Given and new information in the thematic organization of text: An application to the teaching of academic writing. Occasional Papers in Systemic Linguistics, 6(1), 33-43.

Bohnacker, U., \& Rosén, C. (2008). The clause-initial position in L2 German declaratives: Transfer of information structure. Studies in Second Language Acquisition, 30(4), 511-538.

Bohnacker, U. (2010). The clause-initial position in L2 Swedish declaratives: Word order variation and discourse pragmatics. The Nordic Journal of Linguistics, 33(2), 105-143.

Cai, J. T. (1998). The influence of Chinese topic-prominent features on Chinese EFL learners' compositions. Foreign Language Teaching and Research, 4, 17-21.

Canale, M. (1983). From communicative competence to communicative language pedagogy. In J.C. Richards $\&$ R.W. Schmidt (Eds.), Language and communication (2-27). London: Longman.

Chen, X. (2010). Discourse-grammatical features in L2 speech: A corpus-based contrastive study of Chinese advanced learners and native speakers of English. (Unpublished doctoral dissertation). City University of Hong Kong, Hong Kong.
Cheng, X.T. (2002). Cohesion and coherence in English compositions. Journal of School of Foreign Languages Shandong Teachers' University, 2(11), 9498.

Cheng, F.W. (2008). Scaffolding language, scaffolding writing: A genre approach to teaching narrative writing. The Asian EFL Journal, 10(2), 167-191.

Christie, F., \& Dreyfus, S. (2007). Letting the secret out: Successful writing in secondary English. Australian Journal of Language and Literacy, 30(3), 235-247.

Cummings, M. (2003). The role of theme and rheme in contrasting methods of organization of texts. In Butler, C. (Ed.) Dynamics of language use: Functional and contrastive perspectives (129-154). Amsterdam/Philadelphia: John Benjamins.

Daneš, F. (1974). Functional sentence perspective and the organisation of the text. In F. Danes (Ed.), Papers on functional sentence perspective (106-128). Prague: Academia.

Dastjerdi, H. V., \& Talebinezhad, R. M. (2006). Chainpreserving deletion procedure in cloze: A discoursal perspective. Language Testing, 23(1), 58-72.

Ebrahimi, S.F., \& Khedri, M. (2011). Thematicity in research article abstracts: A cross-disciplinary study. Educational Quest, 2(3), 287-292.

Ebrahimi, S. F., E Ebrahimi, S. J. (2012a). Information development in EFL students' composition writing. Advances in Asian Social Science, 1(2), 212-217.

Ebrahimi, S. F., \& Ebrahimi, S. J. (2012b). Markedness in writing: A case of EFL students. Theory and Practice in Language Studies, 2(4), 773-777.

Eggins, S. (2004). An introduction to systemic functional linguistics. London: Continuum.

Gao, W.Y. (2012). Nominalization in medical papers: A comparative study. Studies in Literature and Language, 4(1), 86-93.

Gosden, H. (1993). Discourse functions of subject in scientific research articles. Applied Linguistics, 14(1), 56-75.

Green, C.F., Christopher, E.R., \& Lam, K.M. (2000).The incidence and effects on coherence of marked themes in interlanguage texts: A corpus-based enquiry. English for Specific Purposes, 19, 99-113. 
Halliday, M. A. K. (2000). An introduction to functional grammar. Beijing: Foreign Language Teaching and Research Press.

Hasselgård, H. (2009a). Temporal and spatial structuring in English and Norwegian student essays. In R. Bowen, M. Moberg, \& S. Ohlander (Eds.). Corpora and discourse - and stuff. Papers in honour of Karin Aijmer (93-104). Göteborg: Acta Universitatis Gothoburgensis.

Hasselgård, H. (2009b). Thematic choice and expressions of stance in English argumentative texts by Norwegian learners. In K. Aijmer (Ed.), Corpora and language teaching (121-139). Amsterdam/Philadelphia: John Benjamins.

Hawes, T., \& Thomas, S. (2012). Theme choice in EAP and media language. Journal of English for Academic Purposes, 11, 175-183.

Herriman, J. (2011). Themes and theme progression in Swedish advanced learners' writing in English. Nordic Journal of English Studies, 10, 1-28.

Ho, D. G. E. (2009). Systemic text analysis in the ESL writing classroom: Does it work? RELC Journal, 40(3), 333-359.

Hu, H.Y. (2008). On textual cohesion in Chinese students' English writing. Journal of Zhejiang Normal University (Social Science), 33(3), 113-116.

Hyland, K. (2004). Genre and second language writing. Ann Arbor: University of Michigan Press.

Jalilifar, A. (2010a). Thematization in EFL students' composition writing and its relation to academic experience. RELC Journal, 41(1), 31-45.

Jalilifar, A. (2010b). The status of Theme in applied linguistics articles. Asian ESP Journal, 2, 7-39.

Liu, J.X., E Liu, L. (2013). An empirical study on the application of theme theory in the field of writing pedagogy, English Language Teaching, 6(5), 117128.

Lores, R. (2004). On RA abstracts: From rhetorical structure to thematic organization. English for Specific Purposes, 23(3), 280-302.

Lu, A. (2013). A functional grammar approach to analysing Asian students' writing. American Journal of Educational Research, 1(2), 49-57.
Ma, J. (2001). Thematic progression, cohesive devices and coherence in English writing-- Analysis of CET-4 and CET- 6 writing papers. Foreign Language Education, 22(5), 45-50.

Martinez, I. A. (2003). Aspects of theme in the method and discussion sections of biology journals in English. Journal of English for Academic Purposes, 2(2), 103-123.

Medve, V. B., E Takač, V. P. (2013). The influence of cohesion and coherence on text quality: A crosslinguistic study of foreign language learners' written production. In E. Piechurska-Kuciel, $E$ E. Szymańska-Czaplak (Eds.). Language in cognition and affect (111-131). Berlin: Springer.

Mellos, V. D. (2011). Coherence in English as a second language undergraduate writing: A Theme-Rheme analysis. (Master's Thesis). Retrieved from San Diego State University Library \& Information Access.http:// sdsu-dspace.calstate.edu/handle/10211.10/1287.

North, S. (2005). Disciplinary variation in the use of theme in undergraduate essays. Applied Linguistics, 26 (3), 431-452.

Qian, Y., Andrés Ramírez, J., \& Harman, R. (2007). EFL Chinese students and high stakes expository writing: A theme analysis. Colombian Applied Linguistics Journal, 9, 99-125.

Rørvik, S. (2012). Thematic progression in learner language. In S. Hoffmann, P. Rayson, \& G. Leech (Eds.). English corpus linguistics: Looking back, moving forward (165-177). Amsterdam: Rodopi.

Schleppegrell, M. J. (2004). The language of schooling: A functional linguistics perspective. Mahwah: Lawrence Erlbaum.

Ventola, E. (1994). Finnish writers' academic English: Problems with reference and theme. Functions of Language, 1(2), 261-293.

Wang, L. (2007). Theme and rheme in the thematic organization of text: Implications for teaching academic writing. Asian EFL Journal, 9(1), 164-176.

Wang, X.W. (2010). TP pattern and coherence in English writing: Analysis of TEM-4 writing papers. Foreign Language Research, 2, 103-106.

Wei, J. (2013a). Corpus-based research on the development of theme choices in Chinese learners' English speech. Journal of Education and Practice, 4(16), 38-45. 
Wei, J. (2013b). Corpus-based research on topical theme choices in Chinese and Swedish English learners' English writings. Theory and Practice in Language Studies, 3(12). Forthcoming.
Zhang, Y. H. (2004). Thematic progression and coherence in writing. Foreign Language Learning Theory and Practice, 2, 47-50.

\section{THE AUTHOR}

WEI JING, M.A. in English Language and Literature from Sichuan International Studies University, China, and is currently a PhD candidate in Applied Linguistics from Southwest University, China. She is a full-time lecturer and researcher at School of Foreign Languages, Southwest University, China. 